\title{
Psychological and immunological correlates of acute overtraining
}

\author{
R. W. Fry ${ }^{* \dagger}$ PhD, J. R. Grove ${ }^{\dagger}$ PhD, A. R. Morton ${ }^{\dagger}$ EdD, P. M. Zeroni ${ }^{\dagger}$ BSc(Hons), \\ S. Gaudieri* BSc(Hons) and David Keast* PhD \\ ${ }^{*}$ Department of Microbiology, The QEII Medical Centre, Nedlands, Western Australia; and ${ }^{\dagger}$ Department of \\ Human Movement, The University of Western Australia, Perth, Western Australia
}

\begin{abstract}
Five men undertook two intensive interval training sessions per day for $\mathbf{1 0}$ days, followed by 5 days of active recovery. Subjects supplied a venous blood sample and completed a mood-state questionnaire on days $1,6,11$ and 16 of the study. Performance capabilities were assessed on days 1,11 and 16 using a timed treadmill test to exhaustion at $18 \mathrm{~km} \mathrm{~h}^{-1}$ and $1 \%$ grade. These individuals became acutely overtrained as indicated by significant reductions in running performance from day 1 to day 11 . The overtrained state was accompanied by severe fatigue, immune system deficits, mood disturbance, physical complaints, sleep difficulties, and reduced appetite. Mood states moved toward baseline during recovery, but feelings of fatigue and immune system deficits persisted throughout the study.
\end{abstract}

Keywords: Overtraining, mood, immunity, interleukin-2, psychoneuroendocrinology

It has been suggested that there is an underlying physiological basis for the negative psychological changes that occur in athletes exposed to exercise stress $^{1-3}$. In particular, derangements in immune system function can induce lethargy and depression as well as other psychological states similar to those observed in people suffering from chronic fatigue and the overtraining syndrome $\mathrm{e}^{4-13}$. Similarly, overtraining has been shown to affect the blood concentration of glutamine, dopamine and 5-hydroxytryptamine which are important neurotransmitters, and alterations in these substances have been shown to induce psychological changes, including feelings of chronic fatigue $^{1}$. It is also established that excessive exercise stress can cause imbalanced central nervous system control of certain physiological processes reflected in hypothyroidism, hypothalamic-pituitary dysfunction and deranged immunity ${ }^{14-16}$. Evidence is accumulating that this in turn accounts for many of the symptoms of excessive training and overtraining in athletes including amenorrhoea, increased suscepti-

Address for correspondence: J. R. Grove or A. R. Morton, Department of Human Movement, University of Western Australia, Nedlands, WA 6009, Australia.

Dr R. W. Fry is deceased

(C) 1994 Butterworth-Heinemann Ltd 0306-3674/94/040241-06 bility to infection, and increased susceptibility to stress fractures ${ }^{3}$.

We have previously presented evidence that intensive training can cause perturbations in physiological processes involving the immune system and central nervous system ${ }^{16}$. In this article, we present additional findings on immune system functioning and discuss psychological reactions to acute overtraining. Physiological processes that may be associated with these psychological changes are described, and a rationale for using both physiological and psychological measures to screen for the onset of overtraining is established. Recognition of overtraining in its initial stages may allow intervention and prevent athletes from progressing to a more serious stage of the overtraining syndrome ${ }^{3}$.

\section{Subjects and methods}

Five well-trained men (mean(s.d.) age 31.6(3.5) years) who were familiar with treadmill running gave their written consent to participate in this study. The men were members of the Special Air Services (SAS) Regiment of the Australian Army, which is a regiment of élite troops specializing in tactical response operations. SAS personnel are required to maintain a high level of fitness, and they regularly engage in both endurance and interval (lactic anaerobic) training. The subjects were selected because of their familiarity with intensive physical training and because the nature of their employment allowed them to rest from other physical activity for the duration of the study.

\section{Experimental protocol}

Subjects underwent 10 days of intensive twice-daily interval training sessions followed by a 5-day active recovery period. An abbreviated Profile of Mood States questionnaire developed by Grove and Prapavessis ${ }^{17}$ was administered at 06.00 hours on the first morning of the 10-day training period (day 1), on the sixth day of the training period (day 6), on the day after the completion of the training (day 11), and on the day following the 5-day active recovery period (day 16). A battery of physiological tests and a performance test were also conducted on days 1,11 and 16. 
With the exception of data on interleukin-2, the results of the physiological tests have been published elsewhere ${ }^{16}$. These data are, however, important for this report, and a brief description of the procedures employed is also important. At 06.00 hours on days 1 , $6,11,12,13,14,15$ and 16, 25-ml blood samples were drawn from an antecubital vein before the subjects undertook any exercise. These samples were then assayed for a range of biochemical, haematological and immunological parameters. Mood states were assessed using an abbreviated form of the Profile of Mood States ${ }^{17}$ on days 1, 6, 11 and 16. On days 11 and 16 subjects were also questioned about their general welfare using a free-response format. Subjects were educated as to the effects of carbohydrate and fluid depletion, and they were instructed to drink large quantities of water to an extent beyond which their thirst demanded. They were also instructed to consume a high carbohydrate diet over the full course of the experiment.

\section{Performance assessment and physiological measures}

Subjects underwent a three-stage test on a treadmill to determine work efficiency and time to exhaustion at $18 \mathrm{~km} \mathrm{~h}^{-1}$ and $1 \%$ grade. The first stage consisted of a 4-min run at $12 \mathrm{~km} \mathrm{~h}^{-1}$ with the treadmill set at $1 \%$ grade and then a $3-\min$ rest period. The second stage was a 4 -min run at $15 \mathrm{~km} \mathrm{~h}^{-1}$ (1\% grade), followed by a 3-min rest period. The final stage was a run to volitional exhaustion with the treadmill set at $18 \mathrm{~km} \mathrm{~h}^{-1}, 1 \%$ grade. In order to ensure that subjects had reached $\dot{V}_{\mathrm{O}_{2} \max }$ they were required to achieve a respiratory exchange ratio of 1.15 in this test. Three of eight subjects failed to reach this criterion and were excluded from the experiment. The five remaining subjects achieved this criterion on each of their three performance tests (days 1, 11 and 16).

Heart rates were obtained using a Sportstester $\mathbf{3 0 0 0}$ heart rate monitor (Polar electro, Kempele, Finland) and values recorded were those in the final $10 \mathrm{~s}$ of each work period. Blood samples for subsequent lactate (La) and glucose analysis were obtained from an earlobe previously treated with Finalgon ointment (Boehringer Ingelheim, Melbourne, Australia) to increase earlobe blood perfusion. Samples were collected into 100- $\mu$ l capillary tubes (Analox instruments, London, UK) and obtained within $30 \mathrm{~s}$ of the completion of each work period as well as $7 \mathrm{~min}$ after the final work period. Each of the immediate postworkload samples were analysed for $\mathrm{La}$ and the samples obtained after the final work period were analysed for blood glucose (GLUC). Assays for GLUC and La were conducted on an Analox analyser (Analox instruments) using recommended procedures.

Physiological tests were conducted in an indoor laboratory, and the test of each subject commenced at 07:00 hours. The subjects were requested not to eat or drink fluids except water on the morning of each blood test and to abstain from strenuous exercise for $36 \mathrm{~h}$ before the first test. Gas analysis was conducted throughout the test using a metabolic trolley consisting of an oxygen analyser (Applied Electrochemistry, Sunnyvale, California, USA), carbon dioxide analyser
(Applied Electrochemistry) and ventilometer (Morgan, Gillingham, UK). Peak and submaximal values for oxygen consumption $\left(\dot{V}_{\mathrm{O}_{2}}\right)$ and ventilation $\left(\dot{V}_{\mathrm{E}}\right)$ were determined.

\section{Morning and afternoon training sessions}

The exercise intervention used in this study was designed to place a heavy demand on multiple energy systems and produce a state of acute overtraining. At 06.00 hours on days $2-10$, subjects underwent intensive interval-training sessions. When the subjects first entered the laboratory for the morning sessions, their resting heart rates and body mass were measured. They then undertook a 3-min warm-up run at $12 \mathrm{~km} \mathrm{~h}^{-1}$ followed by $3 \mathrm{~min}$ of stretching and 3 min of running at $15 \mathrm{~km} \mathrm{~h}^{-1}$. After a 1-min recovery period, subjects began their training sessions.

The morning sessions consisted of $15 \times 1$-min work periods separated by 2 -min recovery periods during which subjects were permitted to walk briskly within the laboratory. The work intervals consisted of running at a speed determined from their maximal time achieved on the treadmill during the $18-\mathrm{km} \mathrm{h}^{-1}$ workload of the run to exhaustion on day 1 . If the subjects' time to completion was between $1 \mathrm{~min}$ and $2 \mathrm{~min} 59 \mathrm{~s}$ at $18 \mathrm{~km} \mathrm{~h}^{-1}$, they trained at $18 \mathrm{~km} \mathrm{~h}^{-1}$; between $3 \mathrm{~min}$ and $4 \mathrm{~min} 59 \mathrm{~s}$ they trained at $19 \mathrm{~km} \mathrm{~h}^{-1}$; between $5 \mathrm{~min}$ and $6 \mathrm{~min} 59 \mathrm{~s}$ they trained at $20 \mathrm{~km} \mathrm{~h}^{-1}$; and between $7 \mathrm{~min}$ and $8 \mathrm{~min} 59 \mathrm{~s}$ they trained at $21 \mathrm{~km} \mathrm{~h}^{-1}$. All training sessions were conducted with the treadmill grade set at $1 \%$. Subjects were requested not to engage in any strenuous physical activity between training sessions and were reminded of this daily.

At 04.00 hours on days 1-10, subjects completed 10 $\times 1$-min efforts at the same workload as in the morning sessions. During the afternoon sessions, however, work periods were separated by 1 -min recovery periods rather than 2 -min recovery periods.

\section{Recovery days}

On days $12-15$, subjects reported to the laboratory at 06.00 hours and, after providing a blood sample, had their resting heart rate and body mass recorded. Subjects then undertook $10 \mathrm{~min}$ of unsupervised light running at a time of their choice during the day. They were instructed to run at just above walking pace and to walk if walking was more comfortable.

\section{Questionnaires}

An abbreviated version of the Profile of Mood States (POMS) $^{18}$ was administered on days $1,6,11$ and 16. This scale contained 40 items that assessed the usual POMS subscales of tension, depression, anger, vigour, fatigue, and confusion, as well as an additional subscale for esteem-related affect. The esteem subscale was added in order to tap a positive dimension of mood not normally assessed by the POMS. The instrument has sound internal consistency and discriminant validity, with the mean alpha coefficient for the seven subscales being 0.80 . The 
items associated with each of the seven subscales are described in detail by Grove and Prapavessis ${ }^{17}$. Since short-term mood effects were the focus of this study, we employed the 'how are you feeling today' response set.

\section{Interleukin-2 assay system}

The interleukin-2 (IL-2) assay was adapted from that described by Gearing, Johnstone and Thorpe ${ }^{19}$. In brief, $50 \mu \mathrm{l}$ of CTLL cells at $2 \times 10^{5}$ cells per $\mathrm{ml}$ were seeded into the wells of a 96-well culture plate (Linbro, Horsham, Pennsylvania, USA) and a standard recombinant IL-2 preparation was serially diluted over the cultures. Samples of serum and culture media from peripheral blood leucocytes stimulated with concanavalin A were serially diluted over a similar set of cultures. After $24 \mathrm{~h}$ culture at $37^{\circ} \mathrm{C}$ in a humidified atmosphere of $5 \% \mathrm{CO}_{2}, 0.5 \mu \mathrm{C}$ of 3H-6-thymidine ( $5 \mathrm{Ci} \mathrm{mmol}{ }^{-1}$, Amersham, UK) were added to all wells, and $18 \mathrm{~h}$ later the cultures were harvested on to glass fibre filter (Whatman, Maidstone, UK) using a Skatron cell harvester (Skatron, Lieberyen, Norway) and the radioactivity incorporated into DNA determined by liquid scintillation. The results were expressed as the number of IL-2 units present in the preparations in comparison with the standard curve.

\section{Results}

\section{Statistical analyses}

One-way analysis of variance with repeated measures was used with a Scheffe post hoc comparison being applied to determine significant mean differences. Stringent alpha levels $(P<0.01)$ and a conservative post hoc comparison procedure were selected so as to reduce the chance of type one errors. These precautions were deemed necessary because many parameters were measured in a small sample, and the data had possible clinical implications. Results are presented as mean(s.e.m.) throughout.

\section{Running performance and subjective responses}

The mean(s.e.m.) time taken to reach exhaustion at $18 \mathrm{~km} \mathrm{~h}^{-1}, 1 \%$ grade was $369(33) \mathrm{s}$ on day 1 and was significantly depressed by $29.3 \%$ on day 11 (mean(s.e.m.) 261(27) s). On day 16 performance time had returned toward baseline (mean(s.e.m.) 349(34) s) and was not significantly different from the pretraining level. These changes indicate that the exercise intervention did indeed produce an overtrained state among the subjects. Additional evidence for the existence of an overtrained state comes from the comments made by the subjects on the questionnaire distributed at the conclusion of the training phase. These comments indicated that the subjects were experiencing a variety of physical and psychological difficulties as a consequence of the training regimen. More specifically, they reported a variety of symptoms related to general fatigue, emotionality, concentration, physical complaints, sleep and appetite. (See Table 1.)
Table 1. Symptoms reported during acute overtraining (c.f. Fry et al. 1992) ${ }^{16}$

\begin{tabular}{|c|c|}
\hline Category & Symptom* \\
\hline General fatigue & $\begin{array}{l}\text { Feel lethargic (all) } \\
\text { Exhausted during the day (2) } \\
\text { Ordinary tasks are an effort (2) } \\
\text { Tired in the afternoon (3) } \\
\text { Just walking around is an effort (5) } \\
\text { Getting out of bed is hard (5) } \\
\text { No interest in everyday tasks (5) }\end{array}$ \\
\hline Emotionality & $\begin{array}{l}\text { A bit quick-tempered (1) } \\
\text { Emotionally unstable (2) } \\
\text { Shorter fuse than normal (2) } \\
\text { Snappiness at work (4) } \\
\text { Personality change (5) }\end{array}$ \\
\hline $\begin{array}{l}\text { Concentration } \\
\text { difficulties }\end{array}$ & $\begin{array}{l}\text { Spasmodic concentration (1) } \\
\text { Failure to remember things (2) } \\
\text { Unable to narrow concentration (3) } \\
\text { Difficult to focus/hold concentration (4) } \\
\text { Concentration 'out the window' (5) }\end{array}$ \\
\hline Physical complaints & $\begin{array}{l}\text { Sore muscles (all) } \\
\text { Dehydrated (1) } \\
\text { Heavy feeling in upper legs ( } 2 \text { ) } \\
\text { Stomach complaints/nausea (3) } \\
\text { Loose bowels ( } 3 \text { ) } \\
\text { Diarrhoea (4) }\end{array}$ \\
\hline Sleep problems & $\begin{array}{l}\text { Restless sleeping patterns (1) } \\
\text { Sometimes difficult to get to sleep (2) } \\
\text { Have trouble getting to sleep (4) }\end{array}$ \\
\hline Appetite changes & $\begin{array}{l}\text { Loss of appetite }(1,2) \\
\text { Not able to eat well (4) }\end{array}$ \\
\hline
\end{tabular}

*These are paraphrased versions of actual responses. Numbers in parentheses indicate which subject(s) made each response

\section{Physiological responses}

The data also demonstrate that subjects were under significant physiological stress as a result of the training regimen. Table 2 shows that glucose levels after exercise were suppressed following maximal exercise at the conclusion of the training period (day 11) when compared with values obtained before training (day 1). This effect occurred for glucose values obtained at 1 and $7 \mathrm{~min}$ after exercise, with both measures returning to before-exercise levels after the active recovery period (day 16). Ferritin levels fell progressively over the course of the study. They were depressed, on average, by $11.8 \%$ at the conclusion of the 10-day training period and fell significantly below before-training values by the end of the recovery period. There was an increase in the level of 'activation' of peripheral blood lymphocytes as indicated by significant elevations in the expression of $\mathrm{CD}_{25} 5^{+}$and $\mathrm{HLA}-\mathrm{DR}^{+}$surface antigens as well as a significant depression of the $C D 3^{+}: C D 25^{+}$ratio. These changes were evident on day 6 and persisted at the conclusion of the recovery period.

The presence of natural killer cells $\left(\mathrm{CD}^{+} 6^{+}\right.$cells) in the peripheral circulation was decreased following the training and recovery periods, suggesting that there may have been a redistribution of these cells to tissues damaged by exercise. Mean mitogen responses, in vitro, were also decreased $(14.2 \%$ after day 11 and $30.4 \%$ after day 16), but these changes were not statistically significant. In addition, serum IL-2 levels were significantly elevated following the 
Table 2. Changes in physiological and performance measures during acute overtraining (days 1,6 and 11) and recovery (day 16)

\begin{tabular}{|c|c|c|c|c|}
\hline Parameter & Day 1 & Day 6 & Day 11 & Day 16 \\
\hline $\operatorname{GLUC} 1 \mathrm{~min}\left(\mathrm{mmoll}^{-1}\right)^{*}$ & $8.0(0.3)$ & NA & $6.9(0.4)^{\ddagger}$ & $8.5(0.4)$ \\
\hline GLUC $7 \mathrm{~min}\left(\mathrm{mmoll}^{-1}\right)^{*}$ & $9.0(0.6)$ & NA & $7.3(0.4)^{\ddagger}$ & $9.2(0.4)$ \\
\hline FERR $\left(\left.\mu \mathrm{g}\right|^{-1}\right)^{+}$ & $110(24)$ & $109(24)$ & $97(22)$ & $83(20)^{ \pm}$ \\
\hline $\mathrm{CD}^{2} 5^{+}\left(10^{9} \text { cells }^{-1}\right)^{\dagger}$ & $0.18(0.02)$ & $0.44(0.06)^{\ddagger}$ & $0.52(0.06)^{\ddagger}$ & $0.48(0.05)^{\ddagger}$ \\
\hline HLA-DR ${ }^{+}\left(10^{9} \text { cells } I^{-1}\right)^{*}$ & $0.26(0.02)$ & $0.34(0.04)$ & $0.48(0.07)^{\ddagger}$ & $0.42(0.04)^{\ddagger}$ \\
\hline $\mathrm{CD}^{+} / \mathrm{CD} 5^{+}$(ratio) $^{+}$ & $10.1(0.4)$ & $3.3(0.4)^{\ddagger}$ & $3.0(0.4)^{\ddagger}$ & $3.2(0.3)^{\ddagger}$ \\
\hline $\mathrm{CD} 56^{+}\left(10^{9} \text { cells }^{-1}\right)^{+}$ & $0.60(0.06)$ & $0.32(0.04)^{\ddagger}$ & $0.36(0.05)^{\ddagger}$ & $0.30(0.03)^{\ddagger}$ \\
\hline Serum IL-2 $\left(\mathrm{U} \mathrm{ml}^{-1}\right)^{*}$ & $0.06(0.01)$ & NA & $0.17(0.09)^{\ddagger}$ & $1.00(0.30)^{\ddagger}$ \\
\hline Supernatant IL-2 $\left(\mathrm{U} \mathrm{ml}^{-1}\right)^{*}$ & $0.64(0.20)$ & NA & $5.00(1.23)^{\ddagger}$ & $5.18(1.30)^{\ddagger}$ \\
\hline
\end{tabular}

Values are mean(s.e.m.); FERR, ferritin; GLUC, blood glucose; NA, not available. *Significantly different, $P<0.01$; ${ }^{\dagger}$ significantly different, $P<0.001$; ${ }^{\ddagger}$ indicates significant mean differences from pre-training (day 1 ) values

training period (day 11) and the recovery period (day 16) in both the serum and mitogen-stimulated cell culture supernatants. Plasma glutamine concentrations were significantly depressed on day 6 and day 11 but had begun to return to before-exercise levels by day 16 of the study. Subjects had increasing difficulty completing the prescribed training as the overload training period progressed, and over the last few days they reported feeling nauseous in the final stages of the training sessions (see Table 1).

\section{Mood state responses}

The abbreviated POMS revealed a significant increase in the subscale measuring fatigue after the first 5 days of training. Fatigue scores were elevated even further at the conclusion of the training period (day 11) and then moved toward the baseline during the recovery phase (day 16). The fatigue ratings after recovery were, however, still significantly greater than baseline levels. A significant decrease in vigour and a significant increase in total mood disturbance (TMD) were also evident at the conclusion of training (day 11), with a return toward baseline following the active recovery period (day 16). Confusion scores tended to increase during the training phase $(P<0.05)$, but this change was not significant according to the criterion used in this study. (See Table 3.)

\section{Discussion}

The overtraining and chronic fatigue syndromes are well documented in the medical literature ${ }^{20}$, and they appear to have similar pathogenesis and symptoms ${ }^{3,21,22}$. By examining changes that occur during acute overtraining, we may gain insight into the aetiology of these conditions as well as the interrelationships among the immune system, the central nervous system and the neuroendocrine axis. It is known that increased levels of stress can induce a deranged immunological and neuroendocrine status, and that such imbalances are sometimes associated with psychopathology $y^{6,7,9,12,20,22-25}$. The results of this study indicate that acute overtraining can also cause imbalances in the immune system and, at the same time, produce negative psychological consequences such as mood disturbance, fatigue/lethargy, and (perhaps) an inability to concentrate. Similar symptoms are known to occur in certain psychopathological states ${ }^{12,25}$.

The subjects in this study were clearly overtrained as indicated by significantly depressed performance capacity at the end of the 10-day training period. After 5 days of recovery, running performance moved toward baseline but was still depressed by more than $2 \%$. Changes in the psychological variables supported these performance findings and were consistent with findings from other studies of

Table 3. Abbreviated Profile of Mood States measures during acute overtraining (days 1, 6 and 11) and recovery (day 16)

\begin{tabular}{lcccc}
\hline Subscale & $\begin{array}{c}\text { Before } \\
\text { training } \\
\text { Day 1 }\end{array}$ & $\begin{array}{c}\text { Midtraining } \\
\text { Day6 }\end{array}$ & $\begin{array}{c}\text { After training } \\
\text { Day 11 }\end{array}$ & $\begin{array}{c}\text { After recovery } \\
\text { Day 16 }\end{array}$ \\
\hline Fatigue* $_{\text {Vigour* }}^{*}$ & $0.4(0.2)$ & $9.2(2.4)^{\ddagger}$ & $15.2(1.4)^{\ddagger}$ & $8.0(3.3)^{\ddagger}$ \\
Confusion & $12.4(1.0)$ & $8.0(1.1)$ & $4.0(1.9)^{\ddagger}$ & $7.6(3.2)$ \\
Tension & $0.2(0.2)$ & $1.2(0.7)$ & $2.2(1.8)$ & $1.4(0.7)$ \\
Depression & $4.4(1.2)$ & $1.8(0.8)$ & $2.8(1.2)$ & $2.6(1.2)$ \\
Anger & $0.2(0.1)$ & $0.4(0.4)$ & $1.6(0.7)$ & $1.0(0.8)$ \\
Esteem & $0.2(0.2)$ & $0.4(0.2)$ & $1.0(0.8)$ & $1.2(0.7)$ \\
TMD* & $19.6(0.9)$ & $20.0(1.2)$ & $18.8(1.8)$ & $19.2(1.5)$ \\
& $75.8(3.4)$ & $85.0(2.9)$ & $100.0(5.5)^{*}$ & $87.4(7.6)$ \\
\hline
\end{tabular}

Values are mean(s.e.m.); TMD, Total mood disturbance; ${ }^{*}$ significantly different from day $1(P<0.001)$; ${ }^{\dagger}$ tendency toward difference from day $1(P<0.05)$; \#indicates significant differences from before-training (day 1$)$ values 
overtraining in sport ${ }^{26}$. The comments in Table 1 and the POMS responses (Table 3) show that subjects were experiencing negative psychological states as a consequence of the exercise intervention. All participants referred to concentration difficulties on the open-ended symptoms questionnaire, and the POMS confusion scores tended to increase between day 1 and day 11. In addition, TMD, vigour and fatigue were significantly altered by the training regimen, and fatigue scores remained elevated even after 5 days of active recovery. Blood glucose levels fell significantly between day 1 and day 11 but returned to baseline on day 16. Significant increases in the activation level of peripheral blood lymphocytes $\left(\mathrm{CD} 25^{+}, \mathrm{HLA}-\mathrm{DR}^{+}, \mathrm{CD}^{+}: \mathrm{CD} 25^{+}\right.$ratio) and significant decreases in natural killer cell activity were evident as early as day 6 and were still present after recovery. IL-2 levels also increased in response to the exercise intervention and remained elevated after recovery.

Nonspecific, general activation of the immune system (documented in this study by changes in the CD25 ${ }^{+}, \mathrm{HLA}^{-D R^{+}}, \mathrm{CD}^{+}: \mathrm{CD}^{2} 5^{+}$, serum IL-2, and supernatant IL-2 variables) is accompanied by a range of nonspecific symptoms of illness. These symptoms include loss of interest in usual activities, poor appetite, weight loss, sleep changes, decreased social investigation, loss of energy, fatigue, irritability and anorexia $^{4,10,23,27-32}$. Altered immune status is also known to affect the hypothalamic-pituitary axis $^{7,9,33-39}$ and may be responsible for the hypothalamic-pituitary dysfunction and hypothyroidism known to occur in overtrained athletes ${ }^{14,15}$. Imbalances in these control systems may cause feelings of chronic fatigue and may also be responsible for many of the overtraining symptoms previously reported including amenorrhoea, osteoporosis, and altered testosterone levels ${ }^{3}$. Hypothyroidism has been reported in both the chronic fatigue syndrome and overtraining syndrome $e^{10,15,40-43}$.

We have shown elsewhere that acute overtraining resulted in depressed levels of plasma glutamine for the subjects in this study ${ }^{44}$, and these findings are in agreement with those of Parry-Billings and colleagues $^{1}$ who found depressed plasma glutamine concentrations in overtrained athletes. Glutamine is an important neurotransmitter precursor and is also an essential nutrient for the cells of the immune system $^{45-48}$. Parry-Billings et al. ${ }^{1}$ also found that levels of tryptophan (which is converted in the brain to the neurotransmitter 5-hydroxytryptamine) and dopamine (another neurotransmitter) are both altered under conditions of excessive exercise stress. It is possible that alterations in the concentrations of these neurotransmitters may be partly responsible for the psychological perturbations observed in this study. In particular, there is evidence that 5hydroxytryptamine is the neurotransmitter responsible for causing a state of tiredness and sleep in both man and experimental animals ${ }^{2,49}$.

Plasma ferritin concentrations fell progressively over the course of the experiment to reach their lowest levels on day 16 (Table 2). Chronic hypoferraemia can have immunomodulatory effects and induce feelings of fatigue ${ }^{50-53}$. There may also be a feedback loop involved, because it is known that immune system perturbations can affect the production of ferritin. For example, tumour necrosis factor is a known enhancer of the gene controlling the production of ferritin ${ }^{54}$. Decreased ferritin levels may affect central nervous system processes via an effect on the immune system and by the decreased oxygen delivery which occurs during hypoferraemia.

In summary, psychological and immunological effects from acute overtraining were obtained in this study, but the time course of these effects differed. Changes in immune system activity were apparent after 5 days of intensive training and were still present after 5 days of recovery. POMS fatigue scores followed a similar pattern, but POMS confusion and TMD demonstrated shorter-term changes. On the basis of these findings, we suggest that physiological mechanisms may mediate some of the mood changes associated with overtraining, and that psychological monitoring of overtraining can be useful if supported by physiological measurements. We encourage other researchers to examine psychological and immunological responses to acute and chronic overtraining, since the key to early diagnosis and treatment may lie in this area.

\section{References}

1 Parry-Billings M, Blomstrand E, McAndrew N, Newsholme EA. A communicational link between skeletal muscle, brain, and cells of the immune system. Int J Sports Med 1990; 11: S122-8.

2 Budgett R. Overtraining syndrome. Br J Sports Med 1990; 24: 231-6.

3 Fry RW, Morton AR, Keast D. Overtraining in athletes - an update. Sports Med 1991; 12: 32-65.

4 Lever AML, Lewis DM, Bannister BA. Interferon production in postviral fatigue syndrome. Lancet 1988; ii: 101

5 Rabin BS, Ganguli R, Cunnick JE, Lysle DT. The central nervous system-immune system relationship. Autoimmune Diseases: Clin Lab Med 1988; 8: 253-68.

6 Lloyd AR, Wakefield D, Boughton CR, Dwyer JM. Immunological abnormalities in the chronic fatigue syndrome. Med J Aust 1989; 151: 122-4.

7 Rabin BS, Cohen S, Ganguli R, Lysle DT, Cunnick JC. Bidirectional interactions between the central nervous system and the immune system. Crit Rev Immunol 1989; 9: 279-312.

8 Gorman JM, Kertzner R. Psychoneuroimmunology and HIV infection. Journal of Neuropsychiatry and Clinical Neuroscience 1990; 2: 241-52.

9 Arnason BG. Nervous system-immune system communication. Reviews of Infectious Diseases 1991; 13: S134-7.

10 Buchwald D, Komaroff AL. Review of laboratory findings for patients with chronic fatigue syndrome. Reviews of Infectious Diseases 1991; 13: S12-18.

11 La Via MF, Workman EA. Psychoneuroimmunology: where are we, where are we going? Recenti Progressi in Medicina 1991; 82: 637-41.

12 Grafman J, Johnson R, Scheffers M. Cognitive and moodstate changes in patients with chronic fatigue syndrome. Reviews of Infectious Diseases 1991; 13: S45-52.

13 Sperner-Unterweger B, Barnas C, Fuchs D, Kemmler G et al. Psychiatry Res 1992; 42: 121-8.

14 Barron JL, Noakes TD, Levy W, Smith C, Millar RP. Hypothalamic dysfunction in overtrained athletes. J Clin End Met 1985; 60: 803-6.

15 Lathan SR. Chronic fatigue? Consider hypothyroidism. Physician and Sportsmedicine 1991; 19: 67-70.

16 Fry RW, Morton AR, Garcia-Webb P, Craford GPM, Keast D. Biological responses to overload training in endurance sports. Eur J Appl Physiol 1992; 64: 335-44.

17 Grove JR, Prapavessis $H$. Preliminary evidence for the reliability and validity of an abbreviated Profile of Mood 
States. International Journal of Sport Psychology 1992; 23: 93-109.

18 McNair DM, Lorr M, Droppleman LF. Profile of Mood States Manual. San Diego, California, USA: Educational and Industrial Testing Services, 1971.

19 Gearing AJH, Johnstone AP, Thorpe R. Production and assay of the interleukins. J Immunol Methods 1985; 83: 1-27.

20 Straus SE. History of the chronic fatigue syndrome. Reviews of Infectious Diseases 1991; 13: S2-7.

21 Holmes GP. Defining the chronic fatigue syndrome. Reviews of Infectious Diseases 1991; 13: S53-5.

22 Komaroff AL, Buchwald D. Symptoms and signs of chronic fatigue syndrome. Reviews of Infectious Diseases 1991; 13: S8-11.

23 Kibler R, Lucas DO, Hicks MJ, Poulos BT, Jones JF. Immune function in chronic active Epstein-Barr virus infection. J Clin Immunol 1985; 5: 46-54.

24 Caliguri M, Murray C, Buchwald D, Levine $\mathrm{H}$, et al. Phenotypic and functional deficiency of natural killer cells in patients with chronic fatigue syndrome. I Immunol 1987; 139: 3306-13.

25 Straus SE. The chronic mononucleosus syndrome. J Infect Dis 1988; 157: 405-12.

26 Morgan WP, Costill DL, Flynn MG, Raglin JS, O'Connor PJ. Mood disturbance following increased training in swimmers. Med Sci Sports Exerc 1988; 20: 408-14.

27 Gold D, Bowden R, Sixbey J, Riggs R et al. Chronic fatigue. A prospective clinical and virologic study. JAMA 1990; 264: $48-53$.

28 Hofman FM, von Hanwehn RI, Dinarello CA, Mizel SB, Hinton D, Merrill JE. Immunoregulatory molecules and IL-2 receptors identified in multiple sclerosis brain. I Immunol 1986; 136: 3239-45.

29 McDonald EM, Mann AH, Thomas HC. Interferons as mediators of psychiatric morbidity: an investigation in a trial of recombinant alpha-interferon in hepatitis B carriers. Lancet 1987; ii: $1175-8$.

30 Cheny PR, Dorman SE, Bell DS. Interleukin-2 and the chronic fatigue syndrome. Ann Intern Med 1989; 110: 321.

31 Dantzer R, Kelley KW. Stress and immunity: an integrated view of relationships between the brain and the immune system. Life Sci 1989; 44: 1995-2008.

32 Hall NR, O'Grady MP. Regulation of pituitary peptides by the immune system. Bioessays 1989; 11: 141-4.

33 Besedovsky H, DelRey A, Sorkin E, Dinarello CA. Immunoregulatory feedback between interleukin-1 and glucocorticoid hormones. Science 1986; 233: 652-4.

34 Berkenbosch F, Van Oers J, Del Rey A, Tilders F, Besedovsky $\mathrm{H}$. Corticotropin-releasing factor - producing neurons in the rat activated by interleukin-1. Science 1987; 238: 524-6.

35 Bernton EW, Beach JE, Holaday JW, Smallridge RC, Fein HG. Release of multiple hormones by a direct action of interleukin1 on pituitary cells. Science 1987; 238: 519-21.

36 Sapolsky R, Rivier C, Yamamoto G, Plotsky P, Vale W. Corticotropin-releasing factor - producing neurons in the rat activated by interleukin-1. Science 1987; 238: 522-4.

37 Uehara A, Gottschall PE, Dahl RR, Arimura A. Stimulation of $\mathrm{ACTH}$ release by human interleukin-1B, but not by interleukin-1a, in conscious, freely moving rats. Biochem Biophys
Res Comm 1987; 146: 1286-90

38 Dunn AJ. Systemic interleukin-1 administration stimulates hypothalamic norepinephrine metabolism paralleling the increased plasma corticosterone. Life Sci 1988; 43: 429-35.

39 Dunn AJ. Psychoneuroimmunology for the psychoneuroendocrinologist: a review of animal studies of nervous system-immune system interactions. Psychoneuroendocrinology 1989; 14: 251-74.

40 Borysiewicz LK, Haworth SJ, Cohen J, Mundin J, Rickinson A, Sissons JGP. Epstein-Barr virus-specific immune defects in patients with persistent symptoms following infectious mononucleosus. Q J Med 1986; 58: 111-21.

41 Kroenke K, Wood DR, Mangelsdorff AD, Meier NJ, Powell JB. Chronic fatigue in primary care: prevalence, patient characteristics, and outcome. JAMA 1988; 260: 929-34.

42 Lane TJ, Manu P, Mathews DA. Prospective diagnostic evaluation of adults with chronic fatigue. Clin Res 1988; 36: 714A.

43 Prieto J, Subira ML, Castilla A, Serrano M. Naloxonereversible monocyte dysfunction in patients with chronic fatigue syndrome. Scand J Immunol 1989; 30: 13-20.

44 Keast D, Arstein D, Harper W, Fry RW, Morton AR. Depression of plasma glutamine following exercise and its possible influence on the immune system. Medical Journal of Australia (in press).

45 Newsholme EA, Parry-Billings M. Properties of glutamine release from muscle and its importance for the immune system. Journal of Parenteral and Enteral Nutrition 1990; 14: 63s-67s.

46 Wallace C, Keast D. Glutamine and macrophage function. Metabolism 1992; 41: 1016-20.

47 Keast D, Newsholme EA. Effect of B and T cell mitogens on the maximum activities of hexokinase, lactate dehydrogenase, citrate synthase and glutaminase in bone marrow cells and thymocytes of the rat during four hours of culture. Int $J$ Biochem 1991; 23: 823-6.

48 Griffiths $M$, Keast $D$. The effect of glutamine on murine splenic leukocyte responses to $\mathrm{T}$ - and B-cell mitogens. Immunol Cell Biol 1990; 68: 405-8.

49 Young VR. Kinetics of human amino acid metabolism: nutritional implications and some lessons. Am J Clin Nutr 1987; 46: 709-25.

50 Kushner I. The phenomenon of the acute phase response. Ann N Y Acad Sci 1982; 389: 39-48.

51 Gordeuk VR, Brittenham GM, McLaren GD, Spagnuolo PJ. Hypoferremia in immunosuppressed patients with acute nonlymphocytic leukemia and the risk of infection. J Lab Clin Med 1986; 108: 466-72.

52 Van Asbeck BS, Marx JJ, Struyvenberg A, van Kats JH, Verhoef J. Effect of iron (III) in the presence of various ligands on the phagocytic and metabolic activity of human polymorphonuclear leukocytes. J Immunol 1984; 132: 851-6.

53 Chandra RK, Au B, Woodford G, Hyam P. Iron status, immune responses and susceptibility to infection. CIBA Foundation Symposium 1977; 51: 249-68.

54 Torti SV. The molecular cloning and characterisation of murine ferritin heavy chain, a tumour necrosis factorinducible gene. J Biol Chem 1988; 263: 12638-44. 